\title{
Strategic Management and Technological Innovation in Companies in the Oil Palm Producing Sector
}

\author{
Celedon Ballestas ${ }^{\# 1}$, Raúl J. Martelo ${ }^{* 2}$, Diofanor Acevedo ${ }^{* 3}$

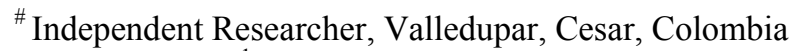 \\ ${ }^{1}$ cballesta@imcos.com \\ * Faculty of Engineering, Faculty of Economics Science, University of Cartagena \\ Cartagena, Bolívar, Colombia. \\ ${ }^{2}$ rmartelog1@unicartagena.edu.co \\ ${ }^{3}$ diofanor3000@gmail.com
}

\begin{abstract}
The behavior of the variables: strategic management and technological innovation in companies producing oil palm in Colombia is analyzed. The methodology is framed under the positivist or quantitative paradigm, with a qualitative approach and with an applied and descriptive level. The sample was formed by eight companies, with two types of population: 90 administrative and 31 managers. The results indicated that the study variables are present in the manager-labor relations of the company.
\end{abstract}

Keyword - Entrepreneurship, labor relations, organizational performance, economic growth

\section{INTRODUCTION}

At present, the economy presents situations of rapid change and each company tries to evaluate the performance constantly, this force to execute steps to expand through new markets, by creating attractive products and prices, satisfying consumers and developing new strategies. Therefore, administrators and executives seek tools and techniques that allow investigating internal and external costs in relation to product / service, obtaining market information, product costs and analyzing customer needs. For the above, organizational performance is a central aspect that addresses strategic management [1].

The study of strategy in organizations is treated as a recent field from the theoretical as well as a practical point of view, with a set of knowledge that is in constant construction, this is noted in the analysis of bibliographic reviews over time. With regard to strategic management, this was born as a hybrid discipline influenced by sociology and economics; in addition, it can be considered as a result of the evolution of theories of organizations, it also emerged as part of strategic planning and the concept of business policy. This concept explains the organization as a system in which economic resources are applied efficiently with coordinated and functional activities of a company to generate income [2].

The other variable of study is technological innovation, which has an impact on an organization and involves analyzing relationships between aspects of the company such as innovation in the organizational and technological field, in the same way, the analysis of performance through the use of theoretical frameworks, this is evidenced in [3], which showed that the variable Organizational innovation favors the development of technological innovation capabilities to obtain greater performance in the elaboration of products and processes. In [4], it was shown that technological innovation is related to the empirical analysis of other business components such as the management of a sustainable supply chain;

This indicates, according to [5] that technological innovation is the capacity of association for technological improvement through the acquisition of business thinking focused on innovation as part of market processes, in search of competitiveness and sustainability.

Therefore, the purpose of this article is to study the behavior and the relationship of the variables Strategic management and Technological innovation to establish the process of implementation and structuring in companies belonging to the oil palm producer sector, in the same way, we analyze how the variables of study are part of labor relations and if they exist or not, in business thinking. In addition, compliance with specific research objectives, dimensions and indicators to verify exist in the sample population is taken into account. The investigative process allows in the last instance, to present conclusions and recommendations for an adequate implementation of strategic management and technological innovation, in addition, to propose guidelines on the business level in order to establish manager-employee relationships, obtain expected results and comply with the market expectations. 


\section{Methodology}

The present investigation was guided by two paradigms: quantitative, which aims to know the object of study through the quantification of magnitudes, the measurement and demonstration of variables and relationships, tends to use instruments of measurement and comparison [6]; and qualitative, limited by the researcher's perception and includes additional perspectives to the object of study, with the purpose of discovering underlying meanings and patterns of relationships [7]. At the methodological level, the type of research was applied and descriptive, the foregoing, catalogs the design of the research as non-experimental and descriptive cross-sectional. In addition, techniques and instruments were used, such as the survey to collect and process statistical data related to palm oil producing companies located in the department of Cesar, Colombia; in order to understand the behavior and compliance of the study variables: Strategic management and Technological innovation.

Because the purpose of the research was to analyze strategic management and technological innovation in companies in the oil palm producing sector in Colombia, this work followed indications proposed by [8]; had an analytical-statistical level that used inferential statistical techniques to draw conclusions, based on a conceptual theoretical level.

\section{A. Population and sample}

The population studied corresponded to companies in the oil palm producing sector in Colombia: Palmagro, Palmas Montecarmelo, Oleoflores, Casacara, Sicarare, Palmeras de la Costa, La Gloria and AgroInce. However, it was necessary to determine the informative units constituted by members of the Administrative Departments and the Executives.

Due to the conditions of the investigation, the sampling selection was made by systematic random sampling, according to [8], it allowed to choose a sample of units of analysis $\mathrm{n}$ from a population $\mathrm{N}$ in three steps:

1) The ratio $\mathrm{N} / \mathrm{n}$ was calculated having obtained $\mathrm{n}$ with the simple sampling equation.

2) The obtained ratio was rounded to an integer $\mathrm{k}$

3) The first analysis unit was randomly chosen between 1 and k; Subsequent units are chosen every k intervals, where $\mathrm{k}$ is a positive number.

According to the list obtained in the National Federation of Cultivators of Palma de Aceite (Fedepalma), the two sample populations were registered (Table 1).

TABLE I. Informative analysis units

\begin{tabular}{|l|l|l|}
\hline Companies in the oil palm producer sector in Colombia \\
\hline Reporting units & Administratives & Managers \\
\hline Business name & 11 & 4 \\
\hline Palmagro & 10 & 4 \\
\hline Palmas montecarmelo & 22 & 10 \\
\hline Oleoflores & 2 & 1 \\
\hline Casacara & 5 & 1 \\
\hline Sicarare & 21 & 6 \\
\hline Palmeras de la costa & 11 & 3 \\
\hline La gloria & 8 & 2 \\
\hline Agroince & 90 people from the administrative area & 31 Managers \\
\hline Totals & \multicolumn{2}{|l}{} \\
\hline 8 companies &
\end{tabular}

\section{B. Data collection}

Among the existing techniques for data collection, content analysis was used, which, according to [9], argue that it is a research technique for the analysis of written or oral records (or other significant matters) for the occurrence of specific categories or events (such as pauses in a speech), items (such as negative comments), or behavior (such as the objective information offered during the group discussion). It was chosen because it showed objectivity in the use of procedures, systematization referring to ordered guidelines that encompassed the observed content and quantification that allowed to numerically encrypt the information for the counting of the units and indicators of the phenomena of interest.

To achieve precision in the results, the technique chosen to collect and analyze data was the "quantitative content analysis", which served as a valid and replicable method through tests of what can be counted in the text in any way (articles, announcements, news, etc.) or other media such as images, television programs, radio or 
movies, and live situations such as interviews, plays, or concerts [6]. The use of the present method was justified by the need to establish analysis dimensions such as: stages of strategic management, determining factors of strategic management, leadership styles in strategic management, components of technological innovation, internal factors of technological innovation and external factors of technological innovation.

In conjunction with the quantitative content analysis, observation techniques were also used in order to have a systematic visualization of the phenomenon and survey, as established by [10], to draw conclusions based on data from a questionnaire made to a significant group of people.

In this case, the survey was made up of a total of seventy-two (72) items, of which thirty-nine (39) will measure the variable Strategic management and thirty-three (33) the variable Technological innovation, which were derived from the study variables, dimensions and indicators; this allowed them to be structured in five (5) Likert scale response alternatives classified as: Always (S), Almost always (CS), Sometimes (AV), Almost never $(\mathrm{CN})$ and Never $(\mathrm{N})$; which was specified in the construction of the Table 2.

TABLE II. Construction of the data collection instrument

\begin{tabular}{|c|c|c|c|c|}
\hline GENERAL OBJETIVE & \multicolumn{4}{|c|}{$\begin{array}{l}\text { Analyze strategic management and technological innovation developed in } \\
\text { companies in the oil palm producing sector in Colombia }\end{array}$} \\
\hline SPECIFIC OBJECTIVES & VARIABLE & DIMENSIONS & INDICATORS & ITEMS \\
\hline \multirow{4}{*}{$\begin{array}{l}\text { Identify the stages of } \\
\text { strategic management in } \\
\text { companies in the oil palm } \\
\text { producer sector in } \\
\text { Colombia }\end{array}$} & \multirow{13}{*}{$\begin{array}{c}\text { STRATEGIC } \\
\text { MANAGEMEN } \\
\mathrm{T}\end{array}$} & \multirow{4}{*}{$\begin{array}{c}\text { Stages of } \\
\text { Strategic } \\
\text { Management }\end{array}$} & $\begin{array}{l}\text { Explore the context } \\
\text { of an entrepreneur }\end{array}$ & 1. 2 and 3 \\
\hline & & & Identify opportunities & 4.5 and 6 \\
\hline & & & $\begin{array}{l}\text { Establish the } \\
\text { organization }\end{array}$ & 7.8 and 9 \\
\hline & & & $\begin{array}{l}\text { Manage the } \\
\text { organization }\end{array}$ & 10. 11 and 12 \\
\hline \multirow{4}{*}{$\begin{array}{l}\text { Describe the determinant } \\
\text { factors of strategic } \\
\text { management in companies } \\
\text { in the oil palm producing } \\
\text { sector in Colombia }\end{array}$} & & \multirow{4}{*}{$\begin{array}{l}\text { Determinant } \\
\text { factors in } \\
\text { Strategic } \\
\text { Management }\end{array}$} & $\begin{array}{l}\text { Diagnosis of } \\
\text { situations }\end{array}$ & 13,14 and 15 \\
\hline & & & $\begin{array}{c}\text { Formulation of } \\
\text { solution alternatives }\end{array}$ & 16. 17 and 18 \\
\hline & & & $\begin{array}{c}\text { Interpretation of } \\
\text { motivation }\end{array}$ & 19. 20 and 21 \\
\hline & & & Shared work vision & 22.23 and 24 \\
\hline \multirow{5}{*}{$\begin{array}{l}\text { Characterize the } \\
\text { leadership styles in } \\
\text { strategic management in } \\
\text { companies in the oil palm } \\
\text { producer sector in } \\
\text { Colombia }\end{array}$} & & \multirow{5}{*}{$\begin{array}{l}\text { Leadership styles } \\
\text { in strategic } \\
\text { management }\end{array}$} & Autocratic & 25.26 and 27 \\
\hline & & & Participatory & 28.29 and 30 \\
\hline & & & Liberal & 31.32 and 33 \\
\hline & & & $\begin{array}{c}\text { Strategic } \\
\text { management }\end{array}$ & 34.35 and 36 \\
\hline & & & Transformational & 37.38 and 39 \\
\hline \multirow{4}{*}{$\begin{array}{c}\text { Describe the components } \\
\text { of technological } \\
\text { innovation in companies } \\
\text { in the oil palm producing } \\
\text { sector in Colombia }\end{array}$} & \multirow{11}{*}{$\begin{array}{c}\text { TECHNOLOGI } \\
\text { CAL } \\
\text { INNOVATION }\end{array}$} & \multirow{4}{*}{$\begin{array}{l}\text { Components of } \\
\text { technological } \\
\text { innovation }\end{array}$} & $\begin{array}{l}\text { Interpersonal } \\
\text { relationships }\end{array}$ & 1.2 and 3 \\
\hline & & & Communication & 4. 5 and 6 \\
\hline & & & Conflict resolution & 7.8 and 9 \\
\hline & & & Coordinate activities & 10.11 and 12 \\
\hline \multirow{3}{*}{$\begin{array}{c}\text { Describe the internal } \\
\text { factors of technological } \\
\text { innovation in companies } \\
\text { in the oil palm producing } \\
\text { sector in Colombia }\end{array}$} & & \multirow{3}{*}{$\begin{array}{l}\text { Internal factors of } \\
\text { technological } \\
\text { innovation }\end{array}$} & Motivation & 13.14 and 15 \\
\hline & & & Attitudes & 16.17 and 18 \\
\hline & & & Values & 19. 20 and 21 \\
\hline \multirow{4}{*}{$\begin{array}{l}\text { Characterize the external } \\
\text { factors of technological } \\
\text { innovation in companies } \\
\text { in the oil palm producing } \\
\text { sector in Colombia }\end{array}$} & & \multirow{4}{*}{$\begin{array}{l}\text { External factors } \\
\text { of technological } \\
\text { innovation }\end{array}$} & Teamwork & 22.23 and 24 \\
\hline & & & $\begin{array}{l}\text { Guidance to the } \\
\text { manager }\end{array}$ & $\begin{array}{l}25.26 \text { y and } \\
27\end{array}$ \\
\hline & & & Program management & 28.29 and 30 \\
\hline & & & Realization of plans & 31.32 and 33 \\
\hline
\end{tabular}

Propose guidelines for the use of strategic management in conjunction with technological innovation in companies in the oil palm producer sector in Colombia 


\section{Validity and reliability of instrument}

For validation of the instrument, the expert judgment technique was used, which had the following procedure: The personnel were selected in the thematic area of study (in a way that corresponds to the variables); each expert received information about: Title of the research, objectives, operationalization of the variable, dimensions and indicators; the observations and recommendations were described in terms of congruence of each item with indicators, variables, and the objectives. In addition to the writing of the items, the information provided by the experts was collected and compared, this allowed the finding of coincidences in the opinions of these, as well as the discrepancies.

On the other hand, to determine the reliability of the questionnaire, the Cronbach Alpha coefficient was used, through the SPSS software, for the Reliability Analysis route.

Likewise, for the measurement of the degree of reliability, a pilot test was performed, which consisted in the application of the questionnaire, but to a specific sample from another sector, with similar characteristics to the object of study.

The method used and applied by means of the pilot test was the Cronbach coefficient (alpha), through Formula 1.

$$
a=\frac{n}{n-1}\left(1-\frac{\sum s^{2} i}{S^{2} t}\right)
$$

Wherein:

$a=$ Coefficient

$n=$ Number of items

$S_{i}^{2}=$ Variance of instrument items

$S_{t}^{2}=$ Variance of the total scores.

With the above equation, the coefficient for the reliability of instruments with continuous items was calculated, which were applied to the subjects of the investigation, to measure the variables: strategic management and technological innovation in companies in the oil palm producer sector in Colombia, with alpha coefficients of 0.96 and 0.95 , respectively.

This implies that the research has validity by showing that the changes observed in the dependent variable are due to the manipulation of the variables, that is, any alternative explanation linked to the phenomenon is discarded. In the same way, it can be generalized to other subjects, moments and situations, for this reason, to understand the degree of reliability the scale of Table 3 is presented.

TABLE III. Scale for interpretation of reliability coefficient assessment

\begin{tabular}{|c|c|}
\hline RANGES & MAGNITUDE \\
\hline 0.81 to 1.00 & VERY HIGH \\
\hline 0.61 to 0.80 & HIGH \\
\hline 0.41 to 0.60 & MODERATE \\
\hline 0.21 to 0.40 & LOW \\
\hline 0.01 to 0.20 & VERY LOW \\
\hline
\end{tabular}

The previous table showed that the results related to strategic management and technological innovation present high reliability.

\section{Data analysis}

Inferential statistical techniques were used to draw conclusions for the entire population from the data of a sample. In addition, for the statistical treatment of the data, tabulation of information was carried out to facilitate the organization of the data related to each study variable. After applying the surveys, the results were tabulated in a double entry matrix that located in the upper margin, each indicator and in the left margin, the subjects surveyed; the summation of each item allowed to obtain the results.

The above, led to the design of a scale to facilitate the interpretation of the tabulated information, each option had an assigned score (Table 4). 
TABLE IV. Scale for the statistical analysis of the mean

\begin{tabular}{|c|c|c|}
\hline ALTERNATIVES OF ANSWERS & QUANTITATIVE VALUES & RANGES OF ANALYSIS \\
\hline Always (A) & 5 & $1-1.80$ \\
\hline Almost Always (AA) & 4 & $1.81-2.61$ \\
\hline Sometimes (S) & 3 & $2.62-3.42$ \\
\hline Almost Never (AN) & 5 & $3.43-4.23$ \\
\hline Never (N) & 1 & $4.24-5.00$ \\
\hline
\end{tabular}

Five (5) attributes to the scale were established, considered in terms of their meaning: never, almost never, sometimes, almost always and always. That is, in correspondence with the alternatives of indicated answers. These attributes indicate the trends about strategic management and technological innovation developed in companies in the oil palm producing sector in Colombia.

Finally, the data collected were treated by the statistical program SPSS to apply Pearson, Spearman and linear regression tests. The first two measure the linear relationship between two quantitative random variables. The third, measures the level of dependence of one variable with respect to the other.

\section{E. Research procedure}

For the development of the research, stages were established that allowed the development of the study. Next, the stages are reflected in the Figure 1.

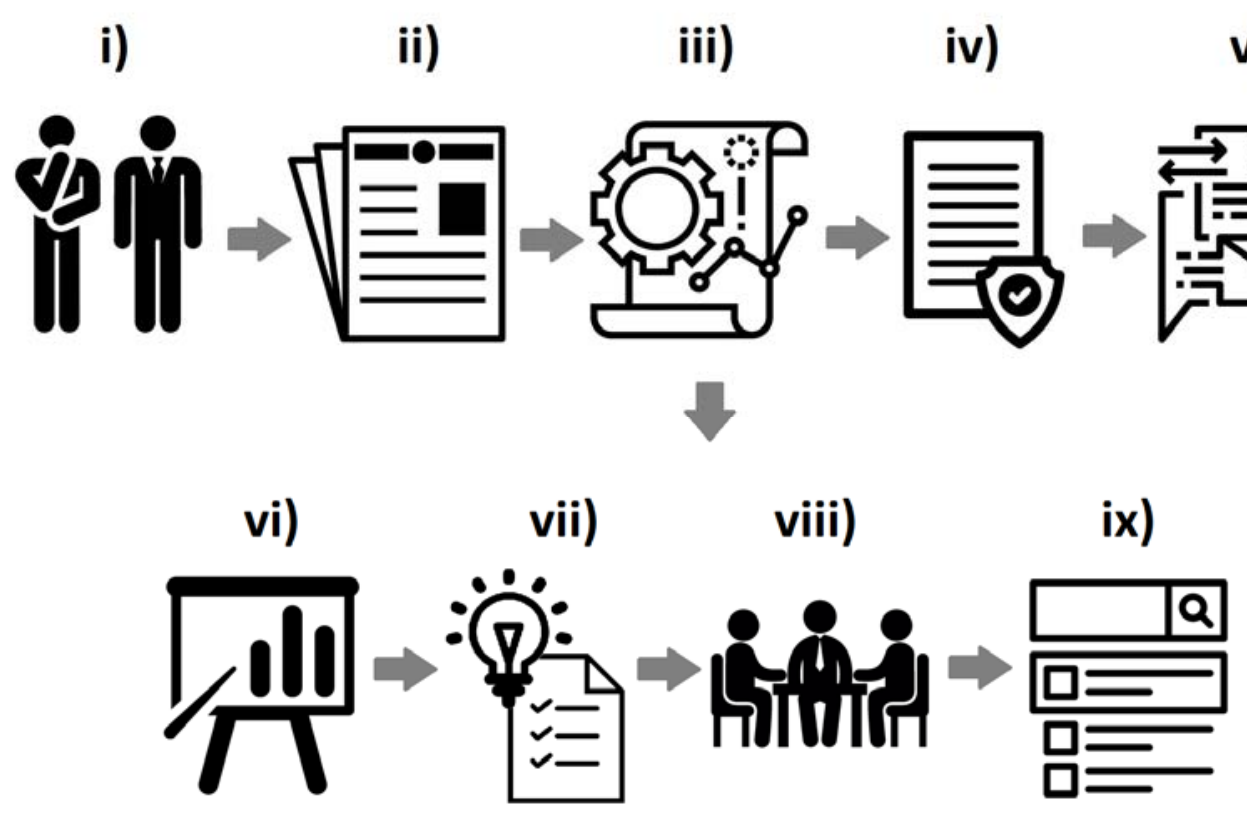

Fig. 1: Stages for the development of research

i) Problem Statement: Aspects related to the problem of interest were investigated through documentary and bibliographic review for the formulation of the problem, the establishment of general and specific objectives. Research was justified from different dimensions: theoretical, methodological, practical and social.

ii) Development of theoretical framework: The bibliographic documentation about the background and theories related to study variables was investigated.

iii) Methodological framework: The design and type of research were decided, taking into account the variables studied. The survey technique was used, in which the information collection instruments used was questionnaire with Likert scales.

iv) Validity and reliability of instruments: adjustments and corrections were made. We proceeded to calculate the reliability, for this a pilot test was applied, for the results the Alpha Cronbach coefficient was calculated, this evidenced that both were reliable.

v) Collection of information: Definitive questionnaires were obtained by means of key informants as workers of the companies subject of the study. 
vi) Analysis of results: The processing and tabulation of data were continued. The results were analyzed by descriptive statistics with the use of measures of central tendency (average), dispersion (standard deviation) and coefficient of variation. For the interpretation of the data, tables of frequencies and percentages with their respective graphs were elaborated.

vii) Generation of guidelines: The corresponding strategic guidelines were generated to improve the performance of the studied variables.

viii) Discussion of results: Comparisons were made with theoretical models and the results of related research in the background of the investigation.

ix) Elaboration of conclusions: Processes of reflection and verification of compliance with the objectives of the research work are carried out, as well as establishing recommendations.

\section{III.RESULTS}

As a case study, this research was conducted with palm oil companies. Below are the results through the steps established in the previous section.

\section{A. i) Problem Statement}

To know the context of the problem of study, it was taken into account that the strategic management exercised by the professionals of the palm oil producer sector is an open topic in global trade and like any organization, the competitiveness it must be increased; this aspect involved each employee, who had to assume specific responsibilities. In addition, technological innovation can complement business adaptation and generate transformations that could be considered as challenges, opportunities or threats to traditional forms of organizational schemes. Therefore, it was necessary to document the experiences and good practices, which would contribute to professionalize and build a Latin American theory on technological innovation, adapted to the conditions of the region and its institutions.

Based on the above, a procedure was carried out to collect data to raise the problem through the application of unstructured diagnostic interviews with managers, supervisors and employees associated with the crop, of companies in the oil palm producing sector of Colombia. The above allowed to find the following: There was no clarity about what were the fundamental purposes of the organization, the direction that followed the strategic management of the company, the person in charge of guiding the decision-making and nor the lines of conduct that should be followed by the personnel in general.

\section{B. ii) Development of the theoretical framework}

This section divided into 3 phases of development: Search of antecedents, in which investigations with similar characteristics were exposed; theoretical bases, the study variables were extended, with their dimensions and indicators; present a system of variables, two main categories were defined in detail.

From the above, the study variables were defined, which are Strategic management and Technological innovation, formed by the dimensions Stages of strategic management, Determining factors of strategic management and Leadership styles in strategic management; and Components of technological innovation, Internal factors of technological innovation and External factors of technological innovation, respectively. Where the dimensions have their own indicators within each variable.

\section{C. iii) Methodological framework}

In this stage the methodological steps to reach the objectives proposed in the investigation were explained; aspects such as the type, level and research design were defined, population and sample was established; In the same way, the techniques and instruments for gathering information, the validity, reliability, the procedures followed throughout the investigation and the data analysis plan.

\section{D. iv) Validity and reliability of instruments}

With the designed instrument, the content was validated through the judgment of a group of experts in the area of study.

Then, the reliability was based on the instrument's ability to record the resulting data on different occasions in the same sample selection. In this case, a pilot test was carried out through questionnaire application, complemented by the statistical method of Cronbach coefficient.

\section{E. v) Collection of information}

Techniques such as observation, interview and questionnaires were used to obtain relevant information, which was interpreted through coding, tabulation and statistical analysis.

F. vi) Analysis of results

On the other hand, to deepen the results obtained from the application of the questionnaires to oil palm companies tables and graphs were designed (Table 2) and in the same way, they allow to understand the information obtained, as can be seen in Table 5 next to the scale of Table 6 . 
TABLE V. Measurement of the Dimension: Stages of Strategic Management

\begin{tabular}{|c|c|c|c|c|c|c|c|c|c|c|c|c|c|c|}
\hline & \multicolumn{14}{|c|}{ Dimension: stages of strategic management } \\
\hline \multicolumn{2}{|c|}{ Response alternatives } & \multicolumn{2}{|c|}{ Always } & \multicolumn{2}{|c|}{$\begin{array}{l}\text { Almost } \\
\text { always }\end{array}$} & \multicolumn{2}{|c|}{ Sometimes } & \multicolumn{2}{|c|}{ Almost never } & \multicolumn{2}{|c|}{ Never } & \multicolumn{2}{|c|}{ Total } & \multirow[t]{2}{*}{$\begin{array}{c}\text { Average } \\
\text { indic. }\end{array}$} \\
\hline Indicators & Items & $\mathrm{AF}$ & $\mathrm{RF} \%$ & $\mathrm{AF}$ & $\mathrm{RF} \%$ & $\mathrm{AF}$ & RF \% & $\mathrm{AF}$ & RF \% & $\mathrm{AF}$ & $\mathrm{RF} \%$ & $\mathrm{AF}$ & $\mathrm{RF} \%$ & \\
\hline $\begin{array}{l}\text { Explore the } \\
\text { context of the } \\
\text { entrepreneur }\end{array}$ & 01-mar & 19 & 66 & 10 & 10 & 34 & 0 & 0 & 0 & 0 & 0 & 0 & 29 & 4.12 \\
\hline $\begin{array}{c}\text { Identify } \\
\text { opportunities }\end{array}$ & 04-jun & 19 & 66 & 10 & 10 & 34 & 0 & 0 & 0 & 0 & 0 & 0 & 29 & 4.28 \\
\hline $\begin{array}{l}\text { Establish the } \\
\text { organization }\end{array}$ & 07-sep & 7 & 24 & 13 & 13 & 45 & 6 & 20.6 & 3 & 10.3 & 0 & 0 & 29 & 3.89 \\
\hline $\begin{array}{l}\text { Manage the } \\
\text { organization }\end{array}$ & 10-dic & 19 & 66 & 7 & 7 & 24 & 0 & 0 & 3 & 10.3 & 0 & 0 & 29 & 3.78 \\
\hline Total dimension & 01-dic & 16 & 55 & 10 & 10 & 34 & 2 & 6.89 & 1 & 3.44 & 0 & 0 & 29 & \\
\hline
\end{tabular}

TABLE VI. Scale for interpreting values of the variable Strategic Management

\begin{tabular}{|c|c|c|}
\hline \multicolumn{3}{|c|}{ SCALE OF INTERPRETATION OF THE AVERAGE } \\
\hline CATEGORIES & RANGES & TOTAL AVERAGE OF THE DIMENSION \\
\hline Very present & $4 \geq 5$ & \\
\hline Present & $3 \geq 4$ & \\
\hline Absent & $2 \geq 3$ & \multirow{2}{*}{ IT IS LOCATED IN A VERY PRESENT CATEGORY } \\
\hline Very absent & $1 \geq 2$ & \\
\hline
\end{tabular}

In this research, each study variable must comply three specific objectives, for example, the Table 5 had the goal of identifying the stages of strategic management in companies in the oil palm producing sector in Colombia; made up of the indicators : Explore the context of the entrepreneur, Identify opportunities, Establish the organization and Manage the organization. For the first indicator, it was shown that $66 \%$ agreed that their own beliefs are shared with that of their co-workers; Regarding the second indicator, $66 \%$ agreed that they always understand that their qualities differentiate them from their other colleagues; for the third indicator it was found that $45 \%$ almost always carry out activities to reinforce the sense of belonging of the employees and for the fourth indicator, it was found that $66 \%$ answered that the human resources department of the organization is dedicated to financial relationships. Then, to complement the previous interpretations, we proceeded to create a graph (Figure 2).

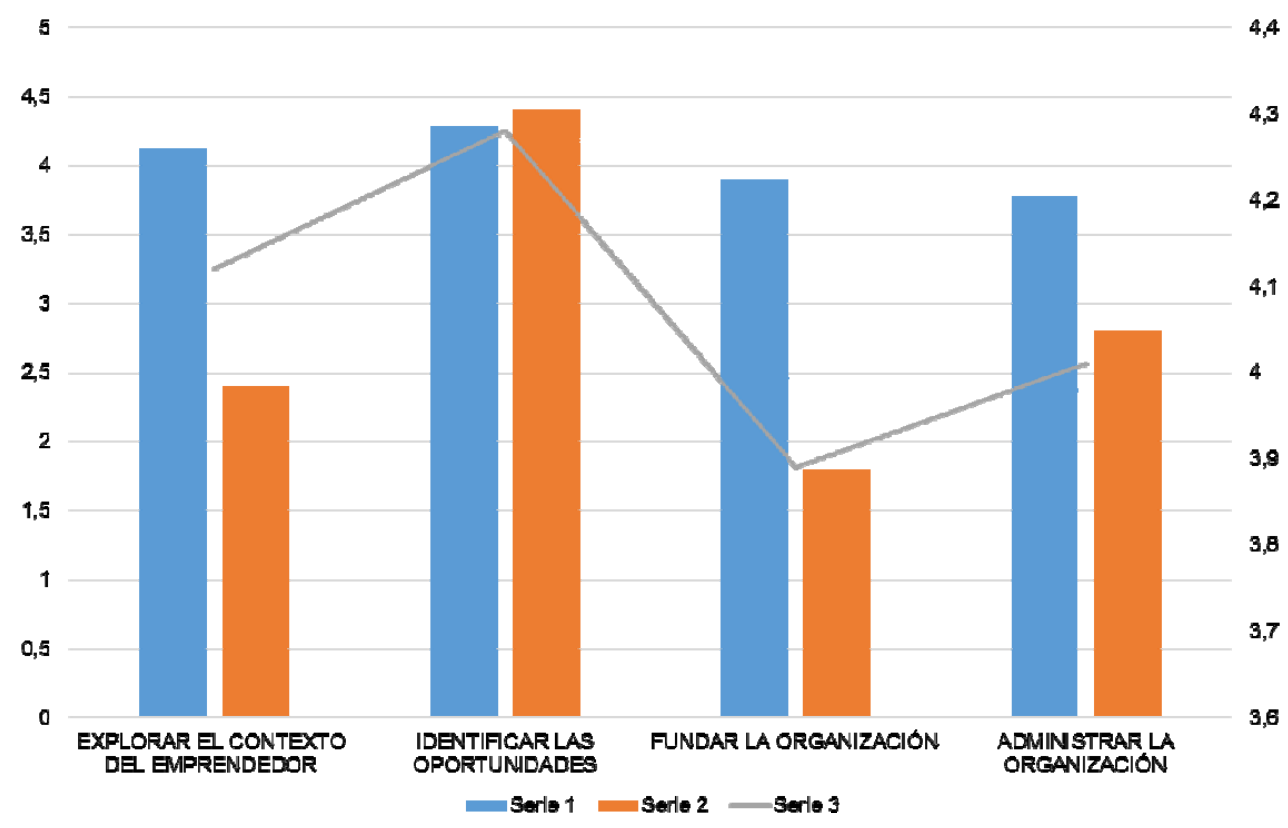

Fig. 2. Dimension interpretation chart - Stages of strategic management 
The graph in Figure 2 allowed to conclude that the dimension studied was an important element in the planning and organizational management around the strategic management of an institution and the operation that it must have.

Regarding the specific objective Describe the determinants of strategic management in companies in the palm oil producing sector in Colombia, and the dimension Determining factors of strategic management, the indicator Diagnostic of situation showed that $79 \%$ of employees take into account the opinions of colleagues, before making a work proposal; the indicator Formulation of solution alternatives showed that 55\% almost always agreed that knowledge negotiation solves problems; regarding the indicator Interpretation of motivation, $79 \%$ affirmed that almost always the work team is motivated and proactive; for the indicator Shared work vision, it was found that $55 \%$ obtain opportunities from their weaknesses to strengthen the professional profile and apply the vision of shared work for the achievement of the negotiations. Therefore, the management of technology aims to establish an awareness of the need to carry out innovations and frequent improvements.

Regarding the specific objective Characterize leadership styles in strategic management in companies in the oil palm producing sector in Colombia and the dimension Leadership styles in strategic management, the indicator Autocratic showed that $90 \%$ agreed to abide by decisions taken by The management; the indicator Participatory showed that $66 \%$ agreed to work with work teams; the indicator Liberal showed that $34 \%$ almost always have spontaneity and flexibility in work activities; the indicator Transformational strategic management showed that $76 \%$ almost always reinvents work strategies. Therefore, this dimension constitutes a step for new development strategies, based on mobilizing technological resources.

Likewise, we proceeded to study the variable Technological innovation with the specific objective Describe the components of technological innovation in companies in the oil palm producing sector in Colombia and the component dimension of technological innovation: The indicator Interpersonal relations, showed that $44.83 \%$, always agree to establish relationships between the discourse and the context in which they operate; the indicator Communication showed that $41.38 \%$ almost always seeks the development of cognitive skills for the creation of work projects; the indicator Conflict resolution, showed that 55\% implement strategies for conflict resolution; the indicator Coordinate activities showed that $90 \%$ almost always determine work activities in relation to the profile of employees. Therefore, a set of strategic ideas oriented to the scope that the company wants through a continuous adaptation is constituted.

Regarding the specific objective Describe the variables of technological innovation in companies in the oil palm producing sector in Colombia and the dimension Internal factors of technological innovation: The indicator Motivation showed that $90 \%$ almost always set objectives that represent aspects derived from the incentive towards achievement; the indicator Attitudes showed that 55\% agree that personal goals always coincide with organizational aspirations; The indicator Values, showed that $100 \%$ assume that ethics is part of the personality of the employee. Therefore, the external factors of technological innovation must be based on a period of reflection based on the answers to a set of questions of two types: those that are related to technology and to the operation of the company; the above in order to achieve a balance between what is intended to be done and the resources available.

Regarding the specific objective To characterize the external factors of technological innovation in companies in the oil palm producing sector in Colombia and the external factors dimension of technological innovation: The indicator Teamwork, showed that $76 \%$ almost always cooperate with co-workers to resolve conflicts; The manager orientation indicator showed that $45 \%$ almost always agree that logical decisions allow the consolidation of effective operations; The indicator Program management showed that $66 \%$ almost always relate personal interests with those of the organization; the indicator of Realization of plans, showed that $66 \%$ always understands the plans of the organization in relation to the circumstances, this leads to an emotional balance.

\section{G. vii) Generation of guidelines}

It was based on each dimension used for this research, it had theoretical and practical purposes focused on strategic management and technological innovation in companies in the oil palm producer sector in Colombia. As a result of the process, the following aspects were proposed: Promote the presence of identification features of the management personnel with the institution; Presence of the feature "benefit ratio" of strategic management as a determinant of technological innovation; Presence of the ethical behavior trait in strategic management for the scope of technological innovation; Presence of the feature "relationship organizational structure/institutional effectiveness"; Presence of strategic management factors in companies in the oil palm production sector in Colombia; Presence of elements of effectiveness in strategic management as support for the improvement of technological innovation that apply to the policies of companies in the oil palm producer sector in Colombia. 


\section{H. viii) Discussion of results}

In this section, discussions are presented about the results obtained respect to the analyzes carried out previously, taking into account dimensions, indicators and research variables.

In the case of the dimension Stages of strategic management, which obtained an average of 4.4, this showed that it exists in strategic management, in addition, this demonstrated that principles of administration or action are executed, through planning, organization, management and control of all activities; demonstrates in the same way, that the manager and employee must fulfill specific roles that lead to obtaining a quality service. From the business point of view, the revision of educational and administrative models is demanded, in order to improve processes and train students as employees to respond to the challenges that society poses.

Regarding the dimension Determining factors of strategic management, an average of 3.97 was obtained, demonstrated that it exists in the variable Strategic management. From the administrative perspective processes of identification, discrimination, understanding and characterization of causes of difficulties are executed, that is, a diagnosis that allows knowing the cognitive and attitudinal status of the administrative staff, as well as detecting possible weaknesses in the worker's performance. This consolidates the application of strategic management practices in order to analyze the competitors [11].

For the dimension Styles of leadership in strategic management, an average of 3.94 was found, it showed that it exists in the variable Strategic management, also that the leader constructs his own knowledge from the mediation of the work colleagues in a particular context that allows project planning; The above agrees with [12], when the search for the process balance consists of having a perspective of the organizational environment governed by four processes: translation of vision, communication and interpersonal relationships, feedback and learning and business planning. Therefore, the manager organizes, guide and motivate the constructivist mental activity of the employees.

In the study of the strategic management variable, the general average was 4.43; this shows that the members that make up the companies work for the fulfillment of the organizational objectives, through skills, responsibility and enthusiasm. According to [11], the above requires an empirical work that generates an efficient system to analyze the competitors, consolidate practices and take advantage of potential roles for business decision making.

Next, the variable Technological innovation is addressed; Regarding to the dimension Component of technological innovation, which had an average of 3.74; from the investigative point of view, it was related to entrepreneurship and business competitiveness; it is taken into account that human capital is a valuable and strategic asset for organizations due to the competitive advantages that can be found in the market. In addition, this is proved by [13], where factors associated with these elements can generate economic growth for the company that applies them, this demands an analysis of the levels of the company. This can be complemented by a process of professionalization and development of social intelligence to create relationships with the general public.

Regarding the dimension Internal factors of technological innovation, an average of 3.56 was obtained, it proved to exist in the variable Technological innovation, this implies that learning processes and the development of social intelligence capabilities are executed within each company through the formation of representative groups, this is corroborated by [14] that addresses a cooperative technological innovation that is capable of addressing risks through the application of systems theory mechanisms as a matrix of analysis for the recognition of key elements. Therefore, the analysis of this dimension breaks down a company into functioning parts, in order to seek a competitive advantage that is achieved when the organization is developed and integrates the activities with less costs and higher performance than the competition.

Regarding the dimension External factors of technological innovation, thus obtained an average of 4.11, showed that it also exists in the variable Technological innovation; likewise, it shows that there is an organizational recognition capacity in companies, this represents a level of analysis to identify value-adding processes determined by incorporating new knowledge. This was applied in the Human Resources Departments to ensure the personal growth of the members of the companies. This is reflected in [15], who studied the implementation of a plan of equitable incentives for employees based on theories of behavior and agents, at the end of the research work, it was demonstrated that technological innovation applied appropriately in the levels of the company, exert positive influence in obtaining organizational results.

To finish with the study of the variable Technological innovation, this had an average of 4.43 , showed that workers have beliefs and values that serve as a basis for proper behavior in situations to be solved; therefore, it is associated with productivity and it is the responsibility of management to have motivated employees to achieve better business performance. 
The previous results showed that the strategic management and technological innovation exist in companies in the oil palm sector, despite the notoriety of the study variables, achievement of objectives, existence of outstanding dimensions and indicators, there are aspects to be improved in order to achieve higher valuations in the sector, there are aspects to work in management-labor relations.

\section{I. ix) Elaboration of conclusions}

Aspects related to the fulfillment of the specific objectives of the research work, based on the analysis and discussion of results were concluded; recommendations were also established such as the following:

- It is convenient to identify the stages of strategic management in companies in the palm oil producing sector to find out if the management work performed meets the organizational needs.

- In relation to describing the determinants of strategic management in companies in the oil palm producing sector in Colombia, it is recommended to develop a greater sense of involvement with the organization.

- Regarding the characterization of leadership styles in strategic management in companies in the oil palm producer sector in Colombia, it is considered that the management style must be defined by the manager, achieving a balance between complying with the rules and listening to the employee.

- To describe the entrepreneurial characteristics of technological innovation in companies in the palm oil producing sector, the interests of employees must be visualized in order to promote the development of their potential.

- To describe the variables of technological innovation in companies in the palm oil producing sector, it is recommended to strengthen inter-institutional ties in order to compare weaknesses and strengths with other institutions and assume aspects that are considered positive.

- To characterize the motivating aspects of technological innovation in companies in the palm oil producing sector, it must be seen how the teamwork is carried out.

\section{J. viii) Discussion of results}

In this

\section{Conclusion}

In relation to the objective of the study, which was oriented towards the analysis of strategic management and technological innovation of oil palm companies in Colombia, the following is concluded:

i) In the identification of the stages of strategic management in companies in the oil palm producing sector in Colombia, it was evident that the aspects related to entrepreneurship in strategic management were positively presented, so that companies in the palm oil producing sector are located in the municipality of Codazzi - Department of Cesar, have progressively followed the aspects that allow efficient human resources management.

ii) The description of the determinants of strategic management in companies in the oil palm producing sector in Colombia was found present, this made evident the companies of the oil palm producing sector of the Codazzi municipality - Department of Cesar, in several aspects that They related to maintaining order in aspects related to human talent, because the weaknesses were shown in the realization of the diagnosis of the reality in which the institutions are immersed.

iii) The description of entrepreneurial characteristics for technological innovation in companies in the oil palm producer sector in Colombia was found in the entrepreneurial characteristics of the personnel, this denoted a sense of self-improvement and an identification with the responsibilities that is related to the growth of training academic.

iv) The description of the variables of technological innovation in companies in the oil palm producing sector in Colombia was present in the motivation of employees in the system of which they are a part, this allowed them to establish real goals that consolidates them at a personal and institutional level. The above was evidenced in a qualified customer service.

v) The characterization of the motivating aspects of the technological innovation, in companies of the oil palm producer sector in Colombia, was consolidated in the technological innovation, this allowed the employee to feel that he can achieve the proposed work goals, which is useful for working individually as a group. 


\section{REFERENCES}

[1] A. Afonina, "Strategic Management Tools and Techniques and Organizational Performance: Findings from the Czech Republic," Journal of Competitiveness, vol. 7, no. 3, pp. 19-36, 2015.

[2] E. Mainardes, J. Ferreira and M. Raposo, "Strategy and strategic management concepts: are they recognised by management students?," E+M Ekonomie a Management, vol. 17, no. 1, pp. 43-61, 2014.

[3] C. Camisón, and A. Villar-López, "Organizational innovation as an enabler of technological innovation capabilities and firm performance," Journal of Business Research, vol. 67, no. 1, pp. 2891-2902, 2014.

[4] V. Lee, K. Ooi, A. Chong and C. Seow, "Creating technological innovation via green supply chain management: An empirical analysis," Expert Systems with Applications, vol. 41, no. 16, pp. 6983-6994, 2014.

[5] B. Mannan, S. Khurana and A. Haleem, "Technological Innovation challenges and opportunities in India and the developing countries," 2015 Annual IEEE India Conference (INDICON), pp. 1-6, 2015.

[6] N. Walliman, Research methods, the basics. Maryland: Routledge, 2011.

[7] E. Babbie, The Basics of Social Research, 5th Edition. Belmont: Cengage Learning, 2011.

[8] F. Kerlinger, and H. Lee, Foundation of behavioral research. Fort Worth: Harcourt College Publishers, 2001.

[9] K. S. Bordens, and B. B. Abbott, Research Design and Methods. A Process Approach, 10th edition. New York: McGraw-Hill, 2018.

[10] R. Kumar, Research Methodology, a step-by-step guide for beginners, 3rd edition. London: SAGE Publications Ltd., 2011.

[11] C. Guilding, K. Cravens and M. Tayles, "An international comparison of strategic management accounting practices," Management Accounting Research, vol. 11, no. 1, pp. 113-135, 2000.

[12] R. Kaplan, and D. Norton, "Using the balanced scorecard as a strategic management system," Harvard Business Review, vol. 74, no. 1, pp. 75-85, 1996.

[13] X. Wang, A. Wang and X. Gao, "Measuring the contribution degree of system and technological innovation to the economic growth," 2016 International Conference on Logistics, Informatics and Service Sciences (LISS), pp. 1-5, 2016.

[14] X. Ge, "Key Element Identification in Cooperative Technological Innovation Risk on Social Network Analysis," 2014 Seventh International Joint Conference on Computational Sciences and Optimization, pp. 316-319, 2014.

[15] M. Li, and T. Wang, "Executive equity incentive and technological innovation," 2014 International Conference on Management Science \& Engineering 21th Annual Conference Proceedings, pp. 1552-1557, 2014.

\section{AUTHOR PROFILE}

Celedon Ballestas works as independent researcher (Colombia). Mr. Ballestas completed his doctorate from Rafael Belloso Chacin University (Venezuela).

Raul J. Martelo works as full-time professor at the University of Cartagena (Colombia). Mr. Martelo completed his magister from Industrial University of Santander (Colombia). Mr. Martelo completed his undergraduate in Systems Engineering at the Industrial University of Santander.

Diofanor Acevedo Correa works as full-time professor in the University of Cartagena (Colombia). Dr. Acevedo completed his doctorate from University of Valle (Cali-Colombia). Dr. Acevedo completed his undergraduate in Food Engineering and Pharmaceutical Chemistry at the University of Cartagena. 